\title{
Peran Hospitalitas Kepemimpinan Bagi Generasi Milenial Di Era Digital
}

\author{
Oktaria Sambolangi' \\ Institut Agama Kristen Negeri Toraja \\ sambolangioktaria@gmail.com
}

\begin{abstract}
Kindness is very important for a leader to have. As Christians, in carrying out their duties as a leader, they need to apply an attitude of friendliness, especially in the church, society, especially for the millennial generation so that people who see it feel comfortable. If hospitality has been implemented in a community or society, it is easier to open up space for people who are still closed. Leaders must build relationships with the community to want to join the community for better progress. In the current millennial era, technology cannot be separated from technology, technology will continue to develop so it takes a leader who can be used as an example because Christian leaders are able to bring change for the better, more beneficial to God and others, because leaders are agents of change, who bring generations to come. Understand new literacy and are not technologically blind. The purpose of this research is to find out what hospitality, leadership, millennial generation is and what is the role of leaders for the millennial generation
\end{abstract}

Keywords: Hospitality, leadership, millennial generation

Abstrak

Keramahan sangat penting dimiliki oleh seorang pemimpin. Sebagai orang kristen dalam menjalankan tugas sebagai seorang pemimpin perlu menerapkan sikap keramahan terutama dalam gereja, masyarakat terutama bagi generasi milenial agar orang yang melihatnya merasa nyaman. Jika keramahan sudah diterapkan dalam sebuah komunitas atau masyarakat, itu lebih mudah membuka ruang bagi orang-orang yang masih tertutup. Pemimpin harus membangun relasi dengan masyarakat untuk mau bergabung dengan masyarakat demi kemajuan yang lebih baik. Di era milenial saat ini tidak lepas dari teknologi, teknologi akan terus menerus berkembang sehingga dibutuhkan seorang pemimpin yang bisa dijadikan contoh karena pemimpin Kristen mampu membawa perubahan kearah yang lebih baik, lebih bermanfaat bagi Allah dan sesamanya, karena pemimpin adalah agen perubahan, yang membawa generasi mengerti literasi baru dan tidak buta teknologi. Adapun tujuan dari penelitian ini adalah untuk mengetahui apa itu hospitalitas, kepemimpinan, generasi milenial dan bagaimana peran pemimpin bagi generasi milenial.

Kata kunci: Hospitalitas, kepemimpinan, generasi milenial 


\section{PENDAHULUAN}

Berbicara tentang kepemimpinan, Kepemimpinan merupakan faktor yang mempengaruhi kberhasilan organisasi dalam mencapai tujuan. Pemimpin yang efektif dapat membawa organisasi mencapai tujuannya. Merupaka sebuah keniscayaan, seorang pemimpin membawa pengaruh besar bagi sebuah organisasi demi mencapai visi yang telah ditetapkan.

Perkembangan teknologi yang begitu pesat telah mendorong terjadinya digitalisasi di semua aspek kehidupan, termasuk dunia kerja. Teknologi juga membuat para generasi mengandalkan media sosial sebagai tempat mendapatkan infomasi. Saat ni sosial menia menjadi platform pelaporan dan sumber berita utama masyrakat. Dengan demikian, sangat menarik membahas tentang kepemimpinan bagi generasi milenial di era digital.era digital akan mendorong generasi milenial untuk lebih dinamis dengan visi perubahan, yang akan melahirkan tuntutan akan sikap hospitalitas kepemimpinan yang berbasis pada teknologi. Era digital adalah istilah yang digunakan dalam kemunculan digital, jaringan internet khususnya teknologi informasi computer.

Fenomena yang terjadi pada tahun 2019-2020 adalah krisis keteladanan kepemimpinan, terutama di era milenial, dimana banyak sekali hal yang terjadi dan arus informasi sangat cepat berkembang sehingga sulit sekali menemukan sosk pemimpin yang berintegritas dan memiliki karakter yang kuat. Pemimpin-pemimpin yang seharusnya memberi teladan, memberi solusi, memberi jawaban disetiap kesulitan yang dihadapi oleh masyarakat malah sibuk dengan kepentingannya sendiri-sendri. Generasi milenial seharusnya mendapatkan keteladanan yang baik dari pemimpinnya dengan melihat gaya kepemimpinannya. Generasi muda seharusnya memiliki hati dan motivasi besar untuk mengembangkan masyarakat dan gereja sesuai dengan perkembangan teknologi agar gereja dan masyarakat dapat tetap relevan dan terus memancarkan kasih dan kemuliaan Kristus di tengah dunia. Metode pembentukan karakter yang relevan dan dapat mencetak generasi milenial yang bisa menjadi pemimpin yang memiliki karakter dan sikap hospitalitas pemimpin Kristen.

\section{TUJUAN DAN MANFAAT PENULISAN}

Untuk mengetahui apa itu hospitalitas, kepemimpinan, generasi milenial dan bagaimana peran hospitalitas pemimpin bagi generasi milenial di era digital.

\section{PEMBAHASAN}

Dalam pembahasan ini yang menjadi bahasan utama adalah bagaimana pengaruh sikap hospitalitas dalam konteks budaya. Hospitalitas merupakan suatu studi yang melibatkan berbagai multidisiplin dalam pencarian pemaknaannya. Dari sisi sejarah, para peneliti memaknai hospitalitas merupakan suatu keramahtamahan dalam masyarakat untuk tidak hanya memberikan akomodasi bagi tamu akan tetapi juga untuk memberikan perlindungan bagi tamu. Dalam kehidupan kita, setiap orang yang 
pernah merasakan kasih Allah dalam hidupnya pasti akan merefleksikan kasih tersebut sebagai suatu bentuk hospitalitas antara individu ke individu lainnya. Sikap hospitalitas ini menjadikan setiap orang tidak membeda-bedakan orang lain Hospitalitas memiliki hubungan yang erat dengan relasi manusia satu dengan yang lainnya. Sikap hospitalitas dapat menghasilkan suatu relasi persahabatan bagi generasi muda.

Untuk menyatakan sikap hospitalitas dengan menyapa dan tersenyum. Karena dengan sikap demikian mereka akan merasa nyaman .

Dalam iman Kristen hospitalitas merupakan kunci penting dalam panggilan kita untuk menjadikan semua bangsa menjadi murid (Mat. 25:31-46). Itulah unsur penting dalam melakukan pewartaan injil dengan integritas .

\section{Kepemimpinan}

Kepemimpinan menurut KBBI (Kamus Besar Bahasa Indonesia) diambil dari kata dasar pimpin, bermakna: cara memimpin. Menurut ahli, kepemimpinan merupakan kemampuan untuk mempengaruhi cara berpikir sesorang sehingga merasa perlu mengambil tindakan tegas dan bertanggung jawab (Parterson, 2015). Dalam konteks luas, kepemimpinan erat kaitannya dengan penugasan yang diberikan seorang pemimpin kepada bawahannya.

Menurut Mulyasa (2004:107), kepemimpinan diartikan sebagai kegiatan untuk mempengaruhi orang-orang terhadap tercapainya tujuan organisasi. Sedangkan kepemimpinan menurut Hasibuan (2010:75) adalah cara seorang pemimpin memengaruhi bawahan, agar mau bekerja sama dan bekerja secara produktif untuk mencapai tujuan organisasi.

\section{Generasi Milenial}

Generasi milenial merupakan generasi yang unik, dan berbeda dengan generasi lain. Hal ini banyak dipengaruhi oleh munculnya smartphone, meluasnya internet dan munculnya jejaring sosial media .ketiga hal tersebut banyak mempengaruhi pola pikir, nilai-nilai dan perilaku yang dianut. Generasi milenial adalah generasi yang "melek Teknologi".

Kehidupan generasi milenial tidak bisa dilepaskan dari teknologi terutama internet, entertainment/ hiburan sudah menjadi kebutuhan pokok bagi generasi ini.

\section{Peran pemimpin bagi generasi milenial di era digital}

Hospitalitas adalah sarana menuju suatu tujuan akhir yang sangat baik. Ketika pemimpinnya memiliki sikap hospitalitas maka generasi pasti bisa melewati tantangan yang ada seiring berkembangnya teknologi. Sikap kepemimpinan yang sangat di butuhkan kaum muda saat ini adalah nilai keramahtamahan dan memiliki digital 
mindset, dimana pemimpin harus memanfaatkan kemajuan teknologi untuk menghadirkan proses kerja yang efisien dan efektif di era digital dan dilingkungan sekitar. Seorang pemimpin juga mampu melihat peluang yang ada, dan cepat beradaptasi serta memfasilitasi perubahan. Hal ini berbeda dengan peran konvensional, dimana pemimpin yang berperan menjadi mentor dan sahabat bagi anggota.

Praktek kepemimpinan berkembang mengikuti perkembangan zaman. Kepemimpinan di era milenial memiliki pendekatan yang khas karena digitalisasi yang menambah dunia kerja tidak lagi memungkinkan pemimpinuntuk bertindak secara konvensional. Unbeatable (pantang menyerah) mindset pantang menyerah tentu harus dimiliki oleh semua pemimpin. Apalagi pemimpin generasi di era milenial yang lekat dengan sikap malas. Dalam menghadapi tantangan teknologi, pemimpin memberikan umpan balik yang akan memampukan generasi memahami siapa dirinya, termasuk kekuatan dan kelemahannya. Pemimpin juga memberikan arahan yang akan membuat generasi mampu menunjukkan kemampuan mereka.

Adapun gaya kepemimpinan yang dimiliki oleh seorang pemimpin untuk memengaruhi generasi milenial. Menurut Beck dan Yeager dalam moeljono (2003:71) adalah yang pertama Telling (directing/structuring) yaitu seorang pemimpin yang senang mengambil keputusan sendiri dengan memberikan intruksi yang jelas dan mengawasinya secara ketat serta memberi nilai kepada mereka yang tidak melaksanakannya sesuai dengan yang diharapkan. Kedua selling (coaching) yaitu seorang pemimpin yang mau melibatkan bawahan atau generasi dalam pembuatan keputusan. Ketiga participating yaitu salah satu ciri dari kepemimpinan ini adalah adanya kesediaan dari pemimpin untuk memberikan kesempatan bawahan/generasi agar dapat berkembang dan bertanggungjawab. Keempat delegating yaitu pemimpin memberikan banyak tanggung jawab kepada bawahan dan memberikan dukungan sepenuhnya untuk memutuskan persoalan.

\section{KESIMPULAN DAN SARAN}

\section{Kesimpulan}

Era generasi milenial merupakan era dimana teknologi menjadi hal yang utama dan mempengaruhi segala aspek, tidak terkecuali kepemimpinan, pola kepemimpinan milenial merupakan pergeseran dari pola kepemimpinan dari generasi sebelumnya. Kepemimpinan era milenial memiliki pendekatan yang berbeda dari kepemimpinan konvensional. Hal ini karena digitalisasi, sehingga kepemimpinan yang konvensional menjadi hal yang kurang efektif untuk generasi milenial. Sikap hospitalitas bagi seorang pemimpin karena dengan itu akan membangkitkan semangat generasi milenial. Sehingga hospitalitas kepemimpinan bagi generasi milenial di era digital mampu menjadikan generasi seperti yang di harapkan atau sesuai dengan tujuan yang akan dicapai. 


\section{Saran}

Pemimpin harus dapat menyesuaikan dengan tuntutan dan perkembangan zaman dalam kepemimpinannya. terlebih pada era saat ini, dibutuhkan pemimpin yang memiliki jiwa dan pemikiran yang visioner serta sikap hospitalitas atau keramatamahan.

\section{REFERENSI}

Panuntun, Daniel Fajar . "Nilai Hospitalitas Dalam Budaya Longko’Torayan.” In Teologi Kontekstual Dan Kearifan lokal Toraja,19,2020.

Panuntun, Daniel Fajar dan Eunike paramita. "Kaderisasi Pemimpin Melalui Pemuridan Kontekstual Sebagai Jawaban Dari Krisis Keteladanan Kepemimpinan.” Kina: Jurnal Kepemimpinan Kristen dan Pemberdayaan Jemaat 1, no.1 (2020).

Panuntun, Daniel Fajar, dan Eunike Paramita. “Hospitalitas Kristen Dan Tantangannya Di Tengah Pandemi Covid-19." Harmoni 19, no. 1 (2020): 67-84.

Soesanto, Heri. Pemimpin Menciptakan Budaya Unggul Generasi Milenial. PT KANISIUS, 2019.

Hariansyah, M. 2018. Milenials Bukan generasi Micin.

Wijoyo, Hadion. Leadership di Era Digital. Insan Cendekia Mandiri, 2021.

Rachmayuniawati, Yuyun, dan Sri Mulyeni. Kepemimpinan Orgsnisasi. Media Sains Indonesia, 2020.

Pohan, Atieq Hasril. "Kepemimpinan Di Era Milenial Ditinjau dari Aspek Komunikasi." Jurnal Komunikasi Islam dan Kehumasan(JKPI), Vol.3,No 2,2019.

Subagyo, Agus. "Kepemimpinan Nasional Untuk Generasi Milenial Di Era Digital.” 